\title{
Teachers' Perceptions towards Impact of Continuous Professional Development Program on Quality Education in Division Gujranwala
}

\author{
Salman Tahir \\ Department of Sociology, GC University, Faisalabad, Pakistan
}

Nazia Malik

Department of Sociology, GC University, Faisalabad, Pakistan

Haq Nawaz

Department of Sociology, GC University, Faisalabad, Pakistan

Norina Jabeen

Department of Rural Sociology, University of Agriculture Faisalabad, Pakistan

Doi:10.5901/ajis.2014.v3n4p395

\begin{abstract}
School improvement in changeable degrees and phases requires change. In order for schools to become successful, they must do effort toward Continuous Professional Development (CPD) which makes powerful teachers to lead this change. The only way schools will improve is through the collaboration that takes place in education communities. One of the purposes of this study was to explore the connections between schools functioning as CPD and increases in student achievement. Continued professional development is recommended for Primary school teachers and Primary schools in the areas that teachers responded to least favorably. Further research should be conducted to examine the relationships among teachers' perceptions based on gender, and age. More professional development is recommended to improve teacher relationships as they relate to increase awareness and improve skills in cultural proficiency and sensitivity. It is the hope that by improving upon the professional development activities and experiences for all primary school teachers, teachers' perceptions about the degree to which their schools function as CPD will be determined by improved practices in teaching and learning.
\end{abstract}

Keywords: Quality education, professional development program, teaching learning and teaching and learning

\section{Introduction}

Education is the most important ingredient in society which plays a vital role in human resource enlargement and for the capacity building. It encourages productivity, public awareness and creates opportunities for the socially, publicly and parsimoniously dispossessed sectors of society. Educational intellectual worried on a learning process through which skills, experience and knowledge are transmitted from one generation to the next generation through research, development, teaching, coaching and training that eventually replicate for the socio-economic change of the country. Education overwhelmed behaviors of the institutional and individual managers effectively for the development / poverty mitigation and prime change of society and supportable economic growth which is a crucial element to initialize of settings for development towards the competitive international public as well. Globalization has made economic life more competitive and demanding, making human capability growth more significant. Only as educated staff fortified with advanced skills can contend and benefit of the opportunities generated by globalization (Pakistan Economic Survey, 2013).

Teachers are always recognized as main players in the education system and therefore professional development of these teachers is crucial, if the quality of education is to be enhanced. Since these teachers are responsible for on condition that quality education to students, there is need for quality professional development programs (Kirmani et al., 2006). Reality is that resolution of a nation is produced in the classrooms. This entails that education is the most important basis of growth and improvement. It can be thought without any hesitation that education is mostly dependable 
for the future of Pakistan. Through quality of education, nation building process for the future citizens of the country is taken place. And it all with happened through only by teachers' professional development. There were the following objectives designed for this research study:

- To find out the difference of opinion about continuous professional development program in division Gujranwala among gender.

- To find out the relationship of continuous professional development and the quality education in public sector in division Gujranwala.

- To find out the prominent opinion of Primary school teachers' towards the continuous professional development program in division Gujranwala

\subsection{Problem Statement}

In research it is clear that the quality of teaching has the major impact on student achievement in the area of learning specially. If we want to promote student achievement and minimize the spaces between groups of kids, the most vital resource to focus on is qualified teachers. Therefore, research demands to be conducted on the sensitivities of Primary teachers regarding the degree to which their schools tasks as per CPD Framework. This study pursues to discover teacher perceptions as they relate to appearances of a CPD.

The information extended from this study also has the potential to inform school leaders about the degree to which their schools serve as CPD and to provide information around possible next stages to their school improvement efforts.

\subsection{Rational of the Study}

The purpose of this study is to determine the perception of primary school teachers in division Gujranwala regarding the degree to which their schools function as per CPD directions. The concept of the CPD is a framework that the school system, as well as the teacher community as a whole, can hold and utilize to facilitate positive change and use to begin to create school communities that spiritually help students become successful. The local culture has always been a most important ingredient of the community, which may have qualities that accompaniment those in a CPD. Therefore, another purpose of this study is to find out the measure to which public schools in division Gujranwala function as CPD Framework.

\section{Literature Review}

This study's literature review covers the work necessary not only to build, but also to maintain CPD in schools. Research in education during the past few decades has revealed various factors affecting student achievement. From external factors such as socioeconomic status and parental involvement to internal factors such as school culture and teacher quality, the nation continues its efforts to improve the education system. Broad research into the determinants of achievement constantly points to parental wages, education, and socioeconomic status as the strong judge as to how well a student does in school (Hanushek \& Lindseth, 2009).

According to DuFour and Eaker (1998), until students take more responsibility for their learning, many educators suggests that schools cannot be more productive. In some cases, this may be true, but for the most part, this argument takes the responsibility for student learning away from the school and places it in the hands of the student. DuFour and Eaker state that some theorists argue that the focus of school reform should shift toward improving the children sent to schools rather than on improving educators and schools. If those in the education community believe that the change must happen externally, then efforts to improve the education system are worthless. On the other hand, for those in education who believe that change is possible and attainable, then the work to be done is achievable. Educators can create the effective schools they are seeking by transforming schools into CPD (DuFour and Eaker, 1998).

According to Whitaker (2004) the concept of school improvement is quite simple, but hard to accomplish. Schools can only change significantly by getting better teachers and by improving them in the schools. If we want our schools to improve significantly, then schools must have Primary quality teachers led by Primary effective principals. Hess, Rotherham, and Walsh (2004) state, Teachers are the key to making schools work.

Primary quality teachers are not born. They are made. The Educational Testing Service (2004) found that a teacher's most important job includes the contributions and enhancements they make to student learning and achievement. The professional growth of most teachers, who remain teaching, happens over time, which helps improve 
teachers.

Darling Hammond (1999) believes that there is a growing body of research that indicates schools can have an impact on student learning. This impact is a result of teachers, even though it was thought traditionally that schools contributed very little to student learning. The school has a great deal of influence when it comes not only to hiring quality teachers but to retaining them as well.

According to Hanushek and Rivkin (2003), when we think about schools, it is difficult not to consider the importance of teachers. Teachers account for a large portion of a school's budget. Thus, teachers play a critical role in determining school quality. The quality of a school is not only dependent upon Primary student achievement, but also on the quality of teachers it has. It is not enough to say that a school is successful because of student test scores. Success also is dependent on the quality of instruction students receive as a result of their teachers.

Hanushek and Lindseth (2009) also state that factors such as the child's ability, parents' education, parent involvement in the education of their child, resources at home, amount of time a child studies, amount of time a child watches TV, motivation of a child, child's health, and other circumstances all contribute to student achievement. There are a variety of factors that affect student achievement, and because school districts spend money on many resources, it is difficult to pinpoint what exactly impacts student achievement. It is unfortunate that throughout the decades, research has not shown a clear connection between student achievement and the amount of money schools spent on education. With the variety of factors that play a role in determining whether a student achieves success, it is important for schools to focus on resources that are at the frontline of student learning teachers.

In CPD, Eaker and DuFour (2002) state that school administrators are perceived as leaders of leaders whereas teachers are perceived as transformational leaders. Every person is a member of a number of many communities, both known and unknown, within society. Schools are also made up of communities. However, as with any community in which relationships also exist, those relationships must be maintained and nurtured on a regular basis, and this requires a conscious and deliberate effort from those involved in the relationships.

Fortunately, teachers are resilient and continually evolving. Schools that provide support and empower teachers will eventually reap the benefits afforded from CPD. Stoll et al., (2006) wrote that support of CPD comes from the teamwork and focus on teacher and student learning that results when teachers and other members of the CPD come together to strengthen the system's capacity to raise standards, reach outcomes, and continue to make improvements that are productive and sustainable. CPD cannot work without commitment and a sense of ownership from those involved. Many schools hear about this new concept of a CPD, but fail to realize, according to Bolam et al., (2005), that the sense of community is at the center of the idea of the CPD. The focus not only targets individual learning, but learning as a community the concept of learning collectively. Schools must change their perceptions and attitudes about the way they are run.

The National Center on Education and the Economy (2007) explained that the heart of the problem is that schools were built for another time when education was needed for workers at the very basic level. There is no amount of money available at any government level to remedy this problem. The only way this problem can be fixed is by changing the system entirely. Change is not easy to embrace, but if schools want to see improvement, change has to occur and the change must first begin from within.

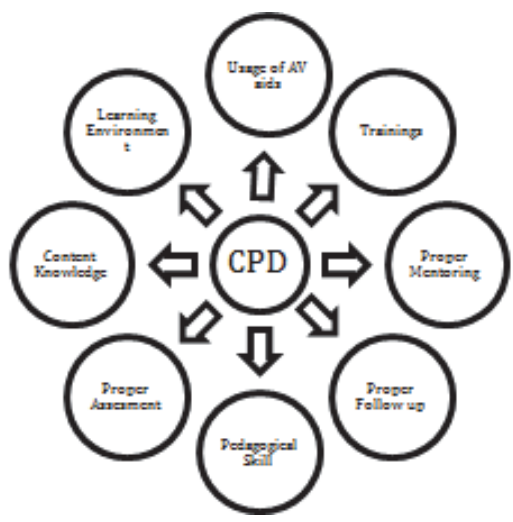




\section{Methodology}

Data analysis is important, as Johnson (2002) states, Data begin to illustrate the gaps between words and actual behavior in many schools. They can also serve as an introduction to the power of data for educators. This study provides data needed to make decisions to improve public schools connected with CPD Framework. More specifically, the purpose of this study is to determine the perception of Primary school teachers (PST) in public schools in Gujranwala Division regarding the degree to which their schools function as per CPD framework directions. The results of this study provide information for determining the kinds of support and resources needed to continue to improve CPD. Research Design and Method of this paper, the quantitative method was selected as the more appropriate method. In addressing the research questions, a quantitative method using survey research was conducted. Research design is directed to allow the researcher to make valid interpretations through comparisons and divisions of those numbers. The survey used in this study provides a comparable measure of teachers' perceptions and the degree to which their schools function as CPD. The consistency of a survey measure enables the researcher to analyze distributions or patterns of association across many subjects. It is important for this study to have a consistent measure in order to make comparisons from one subject to another.

\subsection{Population and Sample}

This quantitative study consists of teachers from the public schools located in district Hafizabad. There are approximately 1481 primary school teachers in district Hafizabad. 100 primary school teachers selected for this research study from the public schools located in the district Hafizabad. It is considered the most efficient and effective method of measuring exact attitude of the respondent. Self-developed questionnaire was used to collect the data. Permission had been taken from the school education department for the smooth conduction of this short research procedure. Two hours time has been allocated to the teachers with delivering instructions for the completion of research questionnaire. Data was analyzed through Statistical Package for Social Sciences (SPSS). Research questions were analyzed using descriptive statistics, means, standard deviation, and t-test to determine significant differences among the means on the survey items. Research questions were analyzed using Pearson correlation to determine the relationship of the survey items.

\section{Results}

This study's purpose was to determine public school teachers' perceptions of the degree to which their schools function as CPD. The study examined whether there were differences among Primary school teachers' perceptions of the degree to which their schools function as CPD.

Table.1: Comparison of opinion towards professional development among gender

\begin{tabular}{cccccc}
\hline & $\mathbf{N}$ & Df & Mean Difference & F & Sig. \\
\hline Male & 116 & 297 & 1.18201 & .039 & .843 \\
Female & 183 & & 1.18201 & & \\
\hline
\end{tabular}

Table shows that there is no significant difference in the opinion towards professional development among gender. It indicates that male and female have the same opinion have the same opinion about the professional development through CPD Framework.

Table.2: Relationship of the continuous professional development and the quality education

\begin{tabular}{cccc}
\hline & & CPD & Quality Education \\
\hline \multirow{2}{*}{ CPD } & Pearson Correlation & 1 & $.703^{* *}$ \\
& Sig. (2-tailed) & & .000 \\
$\mathrm{~N}$ & 300 & 300 \\
\hline
\end{tabular}

**. Correlation is significant at the 0.01 level (2-tailed). 
Above table shows: that there is a positive strong correlation between CPD Framework and quality of education. This shows more the strong will be CPD Framework more the quality of education in the public sector specifically in the primary portion in the publish school in division Gujranwala. Finally, the study examined Teachers' Perceptions towards Continuous Professional Development Program in district Hafizabad there were differences based on teacher traditions, number of years teaching, gender, and age. This was a quantitative study using descriptive and inferential statistical tests to address. For the analysis, descriptive statistics standard deviation and means were used. In addition Pearson correlation was also used. SPSS for Windows was used for the statistical analysis procedures.

\begin{tabular}{lccc}
\hline \multicolumn{1}{c}{ Items } & Yes & To some extent & No \\
\hline CPD framework role a vital role in improving the institutional climate and system & $75 \%$ & $12 \%$ & $13 \%$ \\
Decent amount of improve can be observed after the implementation of CPD & $69 \%$ & $29 \%$ & $2 \%$ \\
Proper follow up of training though mentoring and quality education indicators in field & $53 \%$ & $33 \%$ & $14 \%$ \\
Continuous professional development of PSTs enhance their content knowledge & $61 \%$ & $29 \%$ & $10 \%$ \\
CPD help in the enhancement of pedagogical/instructional skills of PSTs & $38 \%$ & $50 \%$ & $12 \%$ \\
CPD provide the proper mechanism of assessment of students & $51 \%$ & $40 \%$ & $9 \%$ \\
Continuously mentoring of PSTs bring a good change that finally contribute in quality education & $43 \%$ & $52 \%$ & $5 \%$ \\
Practices of usage of AV aids make the learning effective & $40 \%$ & $40 \%$ & $20 \%$ \\
\hline
\end{tabular}

\section{Discussion}

Data from above tables are significant because they tell us that public primary school teachers in division Gujranwala feels very strongly about the degree to which their schools function as CPD. These data reveal areas in which primary schools can work to continue to maintain areas of strength and to strengthen areas that need improvement.

CPD practices can continue to improve and be strengthened with the continued collaboration and work among Primary school teachers. The key to improved teaching and learning is through the implementation of CPD. DuFour (2009) states that in a CPD, teachers are organized into grade level, lessons specific, or interdisciplinary joint teams in which educators work independently to attain common goals for which members are reciprocally accountable. School improvement and professional development go hand in hand. Through CPD, schools can continue to improve and empower teachers to be leaders in their own learning and practices. Each segments of CPD has its own importance and place in the CPD model. Through well-planned professional development and strong CPD, schools can and will continue to improve. Fullan (2001) states, finally, your leadership in a culture of change will be judged as successful or unsuccessful not by who you are as a leader but by what leadership you produce in others.

\section{References}

Stoll, L., Thomas, S., Wallace, M., Greenwood, A., Smith, M. (2006). Creating and sustaining effective professional learning communities. Retrieved from www.dcsf.gov.uk/ research/data/uploadfiles/RR637.pdf

Bolam, L. G., \& Deal, T. E. (2005). Reframing organizations: Artistry, choice, and leadership. San Francisco, CA: Jossey-Bass.

Darling Hammond, L. (1999). Research and rhetoric on teacher certification: A response to teacher certification reconsidered. Retrieved from http://epaa.asu.edu/epaa/ v10n36.html.

DuFour, R., DuFour, R., Eaker, R., \& Many, T. (2006). Learning by doing: A handbook for professional learning communities at work. Bloomington, IN: Solution Tree.

DuFour, R., \&Eaker, R. E. (1998). Professional learning communities at work: Best practices for enhancing student achievement. Bloomington, IN: ASCD.

Eaker, R. E., DuFour, R., \&DuFour, R. (2002).Getting started: Reculturing schools to become professional learning communities. Bloomington, IN: National Educational Service. Educational Testing Service. (2004). Count me in: Quality counts 2004. Retrieved from www.ets.org/Media/News_and_Media/position_paper.pdf.

Hanushek, E. A., \& Lindseth, A. A. (2009). Schoolhouses, courthouses, and statehouses: Solving the funding-achievement puzzle in America's public schools. Princeton, NJ: Princeton University Press.

Hanushek, E. A., and Rivkin, S. J. (2003). How to improve the supply of Primary quality teachers. Retrieved from www.econ.ucsb.edu/ jon/Econ230C/HanushekRivkin.pdf

Johnson, R. S. (2002). Using data to close the achievement gap: How to measure equity in our schools. Thousand Oaks, CA: Corwin Press. Keller, B. (2007, November 7). Teachers seen as making difference in world's top schools. Education Week, p. 8.

Education and the Economy. (2007). Tough choices or tough times: The report of the new commission on the skills of the American workforce. Retrieved from www.skillscommission.org/executive.htm

Pakistan Economic Survey. (2013). Chapter-13 "Education". Retrieved from http://www.finance.gov.pk/survey/chapters_13/10Education.pdf 
Whitaker, T. (2004).What great teachers do differently: Fourteen things that matter most. Larchmont, NY: Eye on Education. Wiersma, W. (2000). Research methods in education: An introduction. Needham Heights, MA: Allyn and Bacon. 